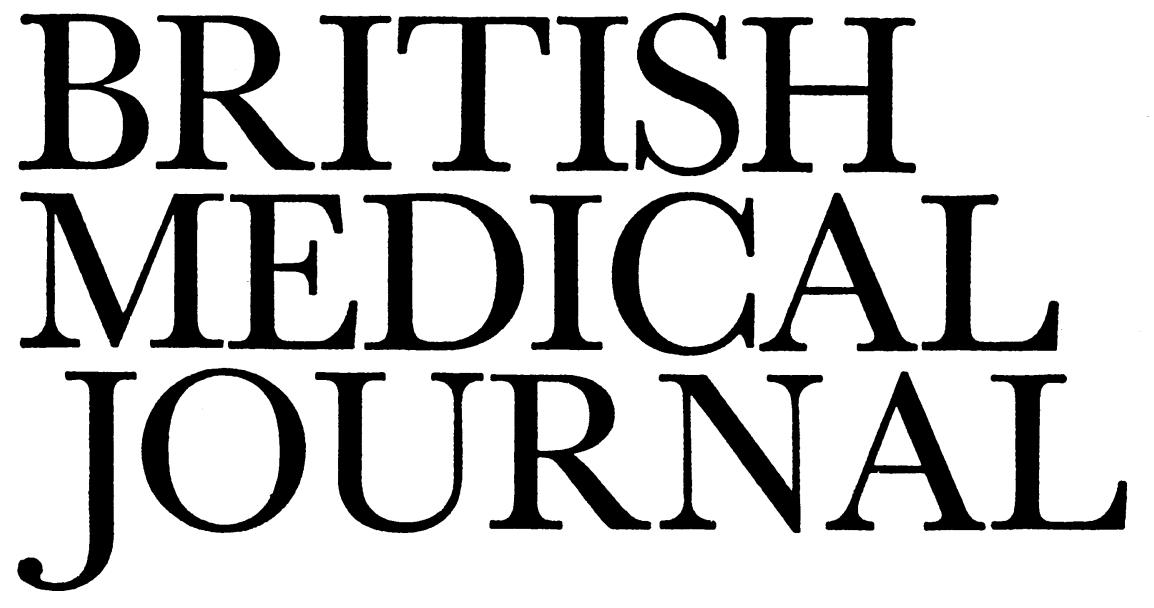

LONDON, SATURDAY 25 JUNE 1977

\title{
Medical Defence
}

\begin{abstract}
"That, as medical men may at any time become liable to false and groundless charges of a ruinous nature, it is most desirable that a Medical Defence Fund be formed and administered in connection with the British Medical Association, and that its members should be asked to contribute a small sum annually to this fund, those who do so becoming entitled, should occasion arise, to legal advice and assistance."1
\end{abstract}

This resolution, adopted by the East Anglian Branch of the BMA in January 1886-three months after the foundation of the Medical Defence Union-was approved by 14 of the Association's 26 branches. ${ }^{2}$ It was then considered by the Council but a year later rejected, as such work could not, apparently, be legally supported from BMA funds. Indeed, the MDU's foundation in the previous year had been held up while the BMA decided whether or not to take part in the new enterprise.

Since then the Medical Protection Society has developed from its birth in 1892 as a splinter group of the $M D U,{ }^{2}$ and the Medical and Dental Defence Union of Scotland was founded in 1901, while on several other occasions the BMA has formally considered whether it should offer medical defence services to members. So the idea of the Association moving into defence had a long history by the time the ARM in London last year resolved: "That the Representative Body notes that in addition to the BMA subscription a member pays dues annually to the GMC and to one of three defence bodies. The Representative Body instructs the Council to investigate the possibility of rationalising the situation and to report back to the Representative Body."

Rationalisation is a vague word that disguises a host of administrative possibilities, from minor office reorganisation to amalgamations and extensive redundancies. It can reasonably be argued that this motion had one of three intentions for the BMA to explore ways of improving co-operation with the defence bodies: to examine a possible amalgamation; to discover if the BMA could negotiate concessions for its members; or to investigate the possibility of the BMA running its own medical indemnity services; or a combination of these. In the event, as the BMA's Secretary's statement at p 1675 spoints out, the Association's officers and officials, following up a vigorous initiative from the BMA's juniors, negotiated a 'draft scheme of professional indemnity insurance with a major commercial insurance broker ${ }^{3}$ and held fresh talks with the defence bodies. What would have helped a profession worried about the future prospects for medical defence in an increas- ingly litigious world was an informed debate on the principles of professional indemnity. Instead, public discussions have been dominated by two issues which, though important and relevant, have unfortunately led to some sharp public exchanges. These are the financial status of the MDU and membership trends in the BMA. The consequence has been a confused and irritated profession. Already harassed by troubles in the NHS and by incomes policies, many doctors have wondered why on earth the long-established defence organisations cannot be left to get on with their job of protecting individual doctors, work which most will agree has been done with diligence, compassion, and an eye for the profession's wider interests.

For some years now, however, doctors have been looking uneasily over their shoulders at medicolegal developments abroad, particularly in the USA-where settlements of millions of dollars are no longer news. While the size and comparative frequency of awards is in part due to the American legal system of contingency fees and in part to the high cost of medical care there, the medical profession in the $\mathrm{UK}$ is bound to ask whether these litigious habits may not spread here. In any case, the size of court awards in Britain is rising rapidly, with the Medical Protection Society's 1976 Annual Report referring to two adverse judgments together requiring "disbursement of nearly $£ 200000 . " 4$ So even if the alleged reinsurance problems of the Medical Defence Union had not been aired last year in Private Eye and The Times and discussed recently in Accountancy $A g e^{6}$ the defence bodies should have been promoting discussions on the future course and likely costs of medical indemnity. Unlike the BMA and the British Dental Association, with their annual public audit by members at representative meetings, the defence bodies' annual "company-style meetings" offer only limited scope for their members to initiate debates on such an important issue of principle.

The defence societies' annual reports provide a comprehensive and entertaining read about the medicolegal pitfalls of daily practice: they are less comprehensive in their narrative accounts of the finances and organisation of the three institutions-tabulated accounts require expert interpretation. Could the BMA, for instance, have been discussing an issue fundamental to its future with a Government department for many months without a reasonably detailed account being given to or demanded by the profession ? Yet, according to the Lancet, $^{7}$ the two London-based defence bodies have been "fighting a Government plan to bring them into line with insurance 
companies," with negotiations "going on with the Department of Trade since last year over a Government plan for the medical defence societies to register as insurance companies under the Insurance Companies Act 1974." The Lancet's parliamentary correspondent also comments that "the Department is anxious that doctors insured with the societies should be adequately covered. Having to register as insurance companies would oblige the societies to meet one of the main requirements of the Act-that the income from premiums exceed the liabilities by one-fifth." Indeed, this article provides us with more information than has so far been forthcoming from the societies themselves, whose recent circular letter to their members, while full of criticism of the BMA's alleged intentions and capabilities, gives doctors little information on the defence bodies' own plans. With their recent annual reports carrying sombre warnings about the difficulties of providing medical indemnity, such a negative approach is both surprising and disappointing.

The defence societies' pique at the BMA's possible encroachment on their territory is understandable. But the threat in the letter that their "continued co-operation with the BMA would be difficult or impossible should the BMA divide the profession by introducing a scheme which is based on the American pattern of malpractice insurance" is not perhaps the best way of putting their case-which surely has sufficient merit by itself. The BMA's Representative Body is mature enough to debate and decide the issue on its merits.

Over the years the three defence societies have not only had close links between themselves-indeed, their subscription increases in step have had a whiff of monopolism about them -but advice and help have flowed in both directions between them and the BMA. How far in recent years the defence societies have displaced the Association in providing personal services to doctors is hard to judge, for the dividing line between their respective responsibilities is fuzzy. Certainly the defence societies have an advantage over the BMA in planning and expanding their services to the profession because they know that doctors must pay their subscriptiors, whereas the BMA's voluntary membership is particularly vulnerable to subscription rises. A combination of inflation and pay restraint is bound to tempt some doctors to "make do" with their compulsory organisations, though such a course is against their real long-term interests. A more constructive approach is to arrange the profession's representative, advisory, and indemnity services as effectively and economically as possible, and doctors must decide whether and how they wish to do this.

Before deciding on this issue, however, the profession should consider the options. There are several questions to be asked:

How do doctors want to be protected against actions for professional error: by competitive mutual schemes (as at present); or by a single, monopoly mutual scheme; or by one or more commercial schemes; or should the State, as employer, provide the cover?

Whatever the choice, should the defence bodies be subject to the Insurance Companies Act, with its requirements of specified reserves and with members legally guaranteed financial cover up to a declared figure ? (The defence bodies do not legally guarantee financial cover or set a ceiling on their liability.)

Are doctors prepared to pay whatever premiums may be necessary for complete cover, including a comprehensive advisory scheme? Or would they be content merely with protection against legal costs and damages?

Are differential premiums that reflect the risks of a particular branch of medicine acceptable or is the more simply administered flat-rate subscription preferable, with low risk doctors subsidising their high risk colleagues?
Should a defence organisation fight a case on an important professional principle even though it would be cheaper to settle?

Does the profession want more say in deciding the policy and the running of their defence societies, including, perhaps, postal elections of their Council members?

Should the defence societies collaborate more closely with the BMA, unite with it, or remain quite separate?

The defence societies are less accustomed than is the BMA to the rough and tumble, give and take, of the public market place. So who can blame them for feeling aggrieved at the BMA for jostling them into the limelight? Comparison with the GMC affair and the subsequent Merrison inquiry would be unfair but there is one common denominator: accountability. Doctors saw the GMC, for which they have to pay, as too remote and unaccountable. The profession, rightly, must fund its own protection: but when financial support is mandatory full representation is the sine qua non. Admittedly, the defence societies have a good record, and, given the profession's initial reactions to the Bowring proposals for indemnity insurance, they are unlikely to be faced with commercial competition yet. But events could alter the profession's mood: consumerism inside and outside the NHS is a trend which seems bound to lead to more litigation and to an increase in NHS inquiries; court awards are rising fast, as are legal costs; and the new contracts being negotiated in the NHS will mean more doctors wanting advice and support in dealing with their employers.

All these developments will cost doctors much more than their present defence society subscription of $£ 40$ a year, however indemnity is organised. Thus it is a matter for the whole profession to discuss-indeed, the community also has an interest-not merely a subject for argument between the BMA and the MDU, MPS, and the MDDUS. So should not the defence societies and the BMA turn their recent differences to the profession's advantage by joining with the British Dental Association and the royal colleges and faculties in sponsoring an independent, interprofessional assessment of defence needs for the '80s? Doctors would surely prefer such a constructive initiative to the present unproductive public fracas.

1 British Medical fournal, 1886, 1, 323.

${ }^{2}$ Forbes, R, Sixty Years of Medical Defence. London, MDU, 1948.

${ }^{3}$ British Medical fournal, 1977, 1, 1297.

${ }^{4}$ Medical Protection Society, Annual Report and Accounts 1976.

5 British Medical fournal, 1977, 1, 385.

Accountancy Age, 1977, 1 (No 19), 6.

' Lancet, 1977, 1, 1270.

\section{Cataract management today}

Patients with cataract occupy much of the ophthalmologist's working week. The growing proportion of the elderly in our population and the trend for patients to be better informed and more articulate than formerly mean that his reputation will rest to a large extent on his management of their problems. Gone are the days when a patient with bilateral cataracts, one mature and the other immature, would meekly accept advice to "go away and come back when you can't see outof the other eye."

In the last three decades real advances have been made in the science and art of cataract surgery, so that nowadays if a cataract is causing appreciable visual loss it should be 